\title{
The Causes of Elderly Residence in Nursing Home from the Viewpoint of Elders
}

\author{
Vahab Karamivand* \\ Department of Aging, Kermanshah University Medical of Science, Kermanshah, Iran
}

*Corresponding author: Vahab Karamivand, Department of Aging, Kermanshah University Medical of Science, Kermanshah, Iran.
Received Date: July 05, 2019

Published Date: September 24, 2019

\section{Abstract}

Background: As the population grows, the demand for long-term care services is expected. since the most important place affecting the elderly, entering into the nursing home, recognizing causes and motivations for staying in the nursing home is important for the establishment of plans to delay or prevent entry elderly to the nursing home. The purpose of this study was to identify the causes of elderly residence in nursing home from the viewpoint of elderly.

Methods: In this study, the phenomenology method has been used. Samples were selected among elderly residents of the Kermanshah state government nursing homes. sampling in this study was purposive method and finally 10 samples were selected. All samples were male and were ranged from 68 to 88 years. the researcher used the interview to collect data. A colaizzis method was used to analyze the data.

Results: In general, the two main concepts derived from the data: 1 Optional Entry 2 Mandatory Entry. Sub-concepts of optional entry include entry with prior approval, entry for financial and family problems, and compulsory entry; entry by deception, unconscious mood, entry by police and social workers, each of which has sub-concepts.

Conclusions: Some elderly people were voluntary resettled because of poverty, lack of shelter and family problems, although some of them were healthy and active, and some were compulsory by family caregivers, police and social workers. By identifying the causes of seniors' residency, recognizing their root needs and problems will be facilitated. And it can also help caregivers in proper planning.

Keywords: Nursing home; Elderly; Residence

\section{Introduction}

The number of elderly people in all societies around the world is increasing. Each year, 1.7 percent is added to the world population. While this increase for the population of 65 years and above is $2.5 \%$ [1]. The country's elderly population is predicted to reach 10 million by 2020 [2]. Given that elderly patients are at high risk for physical deterioration during recovery after Hospitals and are more likely to have long-term care facilities than other age groups. Providing long-term care services after discharge from the hospital is important for the elderly in promoting health and quality of life. Recently, the rate of hospitalization for the elderly 65 years or older is three times as high as for those under 65, and the cost of hospitalization for people aged 65 and older is about $33 \%$ of all hospitalization costs [3]. According to Dorman, it is expected that at least 40 percent of the population over 75 will need extensive health care services at the end of their lives [4]. the problem of the maintenance and welfare of elderly in the society of every day finds new and broader dimensions and statistics show that elderly population in physical, psychological, social, and cultural aspects are constantly required to care for full attention [5].

The term nursing home is used to define institutions that serve people with chronic disabilities and physical defects the focus is on people who do not need hospitalization but are unable to take care of themselves [6]. In other words, people who are unable to stay home due to physical health problems, mental health problems or functional disabilities [7]. On the other hand, the transition to such centers in the study is described as one of the hardest experiences that the elderly encounter [8]. And admission to the nursing home have the mental implications of such as rejection, mental stress, depression, shakiness, loss of home, and the chance of contact with family and friends, so that, among various places, the transfer to the nursing home, in texts, is known to be the most influential place in the elderly [9]. entrance to the elderly has the greatest effect on the 
elderly and fear on the elderly [10]. Institutions by depriving older persons of many of the personal allegiances, which constitute part of his apparent identity, have destroyed his sense of unease [11]. On the other hand, the economic burden on the family and society and the workforce that can be used in simple and non-violent activity is wasted. Moreover, the transition to the residential care house affects both elderly residents and their families. Studies have shown that moving to these centers occurs at times of crisis, for example, after an acute illness or a period of hospitalization. In this situation, the elderly will need to adapt to the new conditions, and this mental stress may be more than that of the elderly [8]. Nowadays, gerontologist do not pay attention to the increased mortality of the elderly, which is an inevitable consequence of being displaced [12]. Thus, countries with a high population of elderly people have developed long-term care policies for the elderly.

The United States and Australia have developed long-term care measures for the elderly with maximum independence [1]. with all of these cases, there is an increasing trend for the elderly to be transferred to nursing home in Iran [13]. Because, as the population ages, more demand for long-term care is expected. Nursing home have traditionally been the most commonly used form of longterm care. Planners are looking for alternatives that are a less expensive form of care for the elderly. Understanding the causes and motivations of staying in the nursing home is important for designing programs to delay or prevent the entry of elderly people into the elderly [14]. Therefore, identifying factors that affect the use of these long-term care services is an important concern. The research question is that what the causes of elderly residence in nursing home from the viewpoint of older persons?

\section{Methods}

In this study, the phenomenological method was used. For data collection, deep and unstructured interviews were conducted over a 4-month period. Samples were selected by purposive sampling method. The researcher selected samples that had sufficient information. 10 samples were selected for this study. all of the samples were male and in the range age of 68 to 88 years. The length of stay varied from 2 months to 15 years. sampling was doing in two governmental nursing home in Kermanshah (Iran), which only accepted the elderly man. Information about the causes of the study was given to the elderly, and all participants received informed consent forms. After the consent of the elderly, places to interview were determined to meet their comfort. Confidentiality of their information and voice was assured. The duration of each interview was set at 20 minutes and finally 30 minutes, as the elderly get tired early [15]. If there were no clear information after the codes were extracted, another interview was conducted for clarification. Finally, 12 interviews were conducted with 10 participants. Some interview questions include" why did you come to the nursing home?" A colaizzis method was used to analyze the data. In the first stage, Recorded sounds were heard several times. And then their statements were word by word written on paper. Then the notes were studied several times to understand their feelings and experiences. In the second step, after studying the extracted materials, the meaningful information related to the title was extracted. For example, the first participant says" I was building and working for a company.

One day I went down the stairs building and got to the hospital. I was 2 months in a coma. When I was fine, they took me home, but my memory was low. My son said I should go back to the doctor, but they had taken me to the notary's office and called my house in his name. And then they took me out of the house. And I came to visit here. I do not know why they did it to me" In the third step, we tried to extract from each statement a concept that expresses its main meaning. During this stage, we constantly tried to ensure the relevance of the meaning of the original sentences and the relationship between them. For example, from the phrases stated, the two concepts of "entry by deception" and "forced entry" were deduced. After extracting the codes of each interview, the next interview was conducted.

The result of this phase of the research consists of 15 codes that are the same concepts as the developed ones. In the fourth stage, the researcher carefully studied the concepts and, based on their similarity, categorized them into thematic categories or main concepts. in the fifth step, for a comprehensive description of the phenomenon under study, the researcher, groups Different subjects with the same meanings were placed in larger subject categories to reach the main concepts. In this way, the structural components of experience, which included two general concepts, were gradually developed. In Diagram No.1, the general concepts of the findings and how they are categorized are presented. In the sixth step, we tried to provide a comprehensive description of the phenomenon under study without ambiguity. The final step was to validate by referring to each sample and asking about the findings [16].

In this research, two criteria of dependability and credibility were used to strengthen the research. In order to confirm the acceptance of the findings, the researcher referred the extracted code to the participants, and with their confirmation, the findings became valid. Furthermore, the researcher referred the findings and the extracted codes to the expert on qualitative research, and in several instances, from the beginning of the analysis, the codes of code formation were examined to reach the main concepts and the validity of the research findings were confirmed. In addition, the researcher explained the research process and how to achieve the results to be sure of the finding, so that other researchers can understand how to achieve the results [17].

\section{Results}

In general, the findings from the residence had two general concepts, five sub-concepts, and 15 codes. The two main concepts extracted were optional entry and Compulsory entry. Sub-concepts of optional entry included entry with prior approval and entry due to financial and family problems. Sub-concepts of forced entry included entry by deception, entry in Unconscious mode, and entry by government agencies. Each of these sub-concepts has the codes described (Figure 1). 


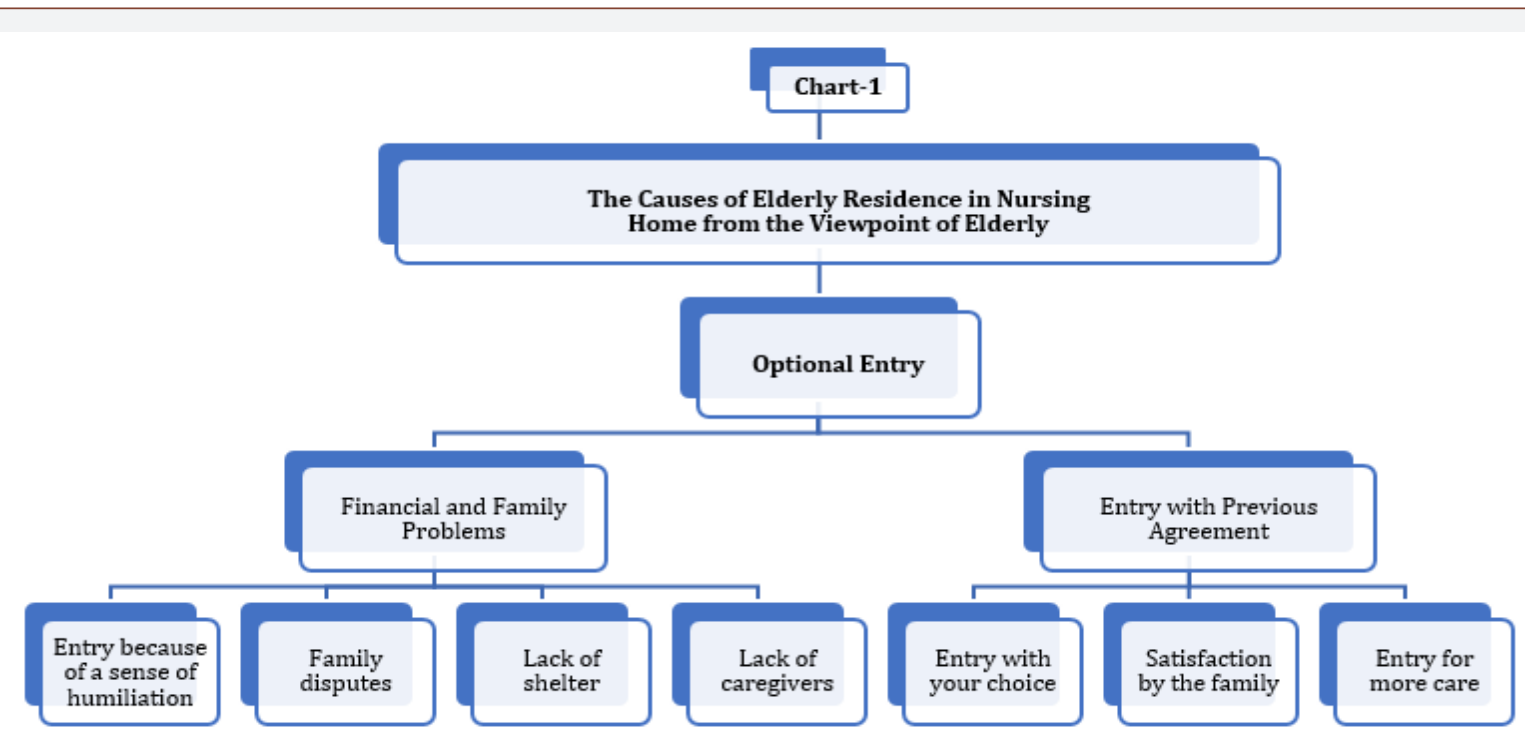

Figure 1: Optional entry.

\section{Optional entry}

Entry with prior approval: Some research samples have stated that they have come here with their desire and choice" When some of them were asked how you came to nursing home?" They responded to the researcher. I came to my own will. I lived alone at home. Someone has not forced me. I'm friends now that I am here and I'm happy. But the participant \# 3 in the answer says that after my legs broke and I was discharged from the hospital. I did not take care of my children at home, and I heard that these centers take care of the elderly. Now that our body is fine. My family does not get me home.

Entry due to financial and family problems: Some elderly people mentioned the reason for entering the old age as family problems, for example, one of them says that I have two boys who married and live in front of me, my wife died, my boys and brides spend my salary and something It does not stay for me. Sometimes I realize that my brides are grumbling about me and saying your father should go to this house. Or participant No.2 in the answer says I was sleeping on the street before I came to this place, and I begged for days. I'm not married, I have no children. One day I was looking for a place to take care of me and I could sleep comfortably and give me water and food. And I got it from here (Figure 1).

\section{Mandatory entry}

Entry with deception: Participant No.4 says that my son said we should take you to the doctor. So, to see the fracture of the leg was good or not, we were on the way for three hours and night. I gave a place and said I was going to take your medicines, but it did not return.

Entry in unconscious mood: One of the elderly states that I was not very well off when I was discharged from the hospital. One of my sons took me to the office and took a fingerprint from me. And a few days later I was taken out of the house.

Entry by government agencies: Participant No. 7 says I had rented a room and I was busy begging for days. My house was full of rubbish and I could not clean it. The neighbors complained to me and called the police. And they delivered me to the social agency. I loved my house and I want to go back (Figure 2).

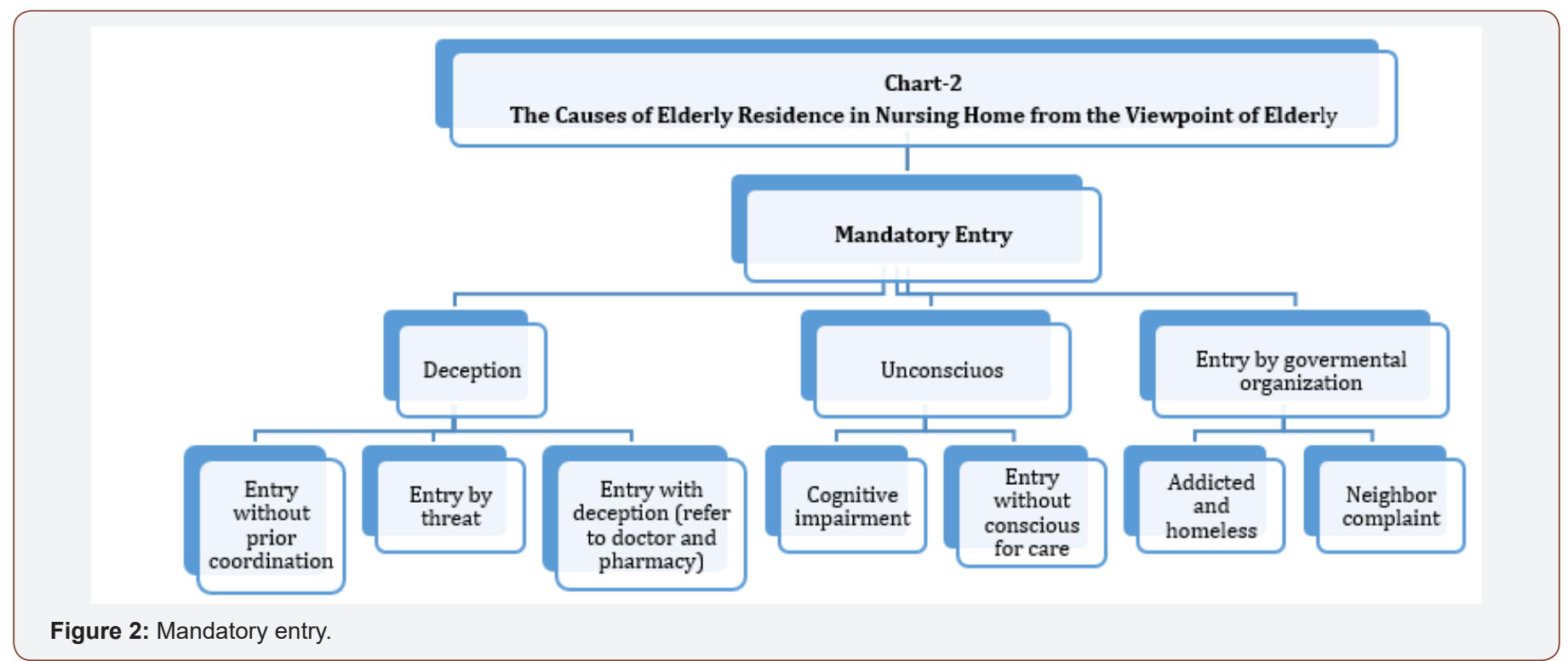




\section{Discussion}

In this study, some elderly people were settled in nursing homes due to family problems and financial inability. Findings from the study by Sao and Hallis showed that family pressure, feeling of security, using formal and informal services, and a feeling of health degradation lead the elderly to stay in the nursing home, and is consistent with the results of the researcher's study [18,19]. Also, many older people have not the ability to pay home expenses such as house maintenance, or older might want to move somewhere else. But they do not have the necessary capital to move, and they inevitably prefer to stay in the nursing home [20]. on the other hand, elderly people who live alone are more likely to seek accommodations for social contact with others. therefore, for older adults living alone before acceptance, positive outcomes were expected [9]. In the present study, some elderly people said they had been forced into the nursing home. For example: stay without notice, or stay deceived, stay in a state of illness and stay for taking care. While studies show that elderly people prefer to recover the disease in their place of residence instead of the elderly. When the mental and physical abilities of the elder are getting worse, and family resources or society is not available for a long time, admission to the elderly is required [18].

Findings of the study by Shiva et al. Showed that in addition to previous hospitalization, caregivers' willingness to stay in the nursing home is a determinative factor in the use of nursing homes after hospital discharge [3]. In this study, one of the ways of entering the elderly into nursing home is entering in state of Unconscious following cognitive impairment, which is consistent with the findings of the study by Wang et al [22]. Another reason for the elderly's stay in this study is the lack of proper care after discharge from the hospital. For example, one of the participants stated: "When my pelvis broke down and I was in hospital for about one month, they said that to go home for home care, "at home there was no one to pay attention to my daily needs. There was not even anyone to give me a glass of water and I decided to go to the nursing home to continue to care. "In analyzing these statements, it can be stated that elderly people, given their high needs, especially when they are recovering from illness, should be given more attention so that the recovery process does not go back. These results are consistent with the findings of the Abbasid study and Colleagues [23].

\section{Conclusion}

From the findings of this study, it is concluded that factors such as cognitive impairment, physical illness, financial problems, family disputes, sense of humiliation, lack of care, and lack of shelter lead to elderly people staying in nursing home. Some elderly people, despite being active and healthy, had to stay at the nursing homes due to financial problems. And they complained about not having any activity at the nursing home. It seems that if social support is appropriately done, then these elderly people can live in their homes. A number of elderly people were involved in financial abuse. While they have had the necessary capital for a good life, there seems to be no comprehensive organization that supports the elderly in such cases. Coherent social support, government agencies, self-care education and the preservation of autonomy in the elderly, and the training of family caregivers and their support may reduce the entry of elderly into old age. Unwillingness to cooperate, illiteracy, early exhaustion, fear of reviewing past bitter memories were the limitations of this study.

\section{Financial Support and Sponsorship}

Kermanshah University of Medical Sciences supported this article.

\section{Conflict of Interest}

No Conflict of interest.

\section{References}

1. Cho SH (2005) Older people's willingness to use home care nursing services. J Ad Nurse 51(2): 166-173.

2. Arab M, Tajour M (2006) Study of the status of elderly health care services in Iran. Quarterly Journal of Hospital 6(1): 6-8.

3. Streubert HJ, Carpenter DR (2011) Qualitative research in nursing: advancing the humanistic imperative. Philadelphia: Lippincott Williams and Wilkins.

4. Matlabi H, Parker SG, McKee K (2011) The contribution of home-based technology to older people's quality of life in extra care housing. Biomed Central Geriatrics 11: 68

5. Tajour M (2003) Elderly health and review of different aspects of their lives. Tehran: p: 1-46.

6. McKee K, Matlabi H, Parker SG (2012) Older people's quality of life and role of home-based technology. Health Promot Perspect 2(1): 1-8.

7. McEwen M (2002) Community-based nursing: an introduction. $\left(2^{\text {nd }}\right.$ edn.), Philadelphia: Saunders. p: 1-94.

8. Lee DT, Woo J, Mackenzie AE (2002) A review of older people's experiences with residential care placement. J Adv Nurs 37(1): 19-27.

9. Eliopoulos C (2013) Gerontological nursing ( $8^{\text {th }}$ edn.), Philadelphia: Lippincott Williams and Wilkins, Pennsylvania.

10. Eshaghi R (2004) Introduction to the Proceedings of the Seminar on Allergy of Isfahan. Esfahan: Isfahan University of Medical Sciences. p: 2.

11. Lueckenotte AG (2004) Gerontological nursing ( $2^{\text {nd }}$ edn.), ST. louis: mosby pp: 1-213.

12. Miller CA (2004) Nursing for wellness in older Adults theory and practice ( $4^{\text {th }}$ edn.), Philadelphia: Lippincott Williams \& wilkins, pp: 1-142.

13. Salarvand SH, Abedi Heydar A, Shamloo K (2007) Experience of powerlessness in the elderly living in the elderly. Iranian Journal of Nursing 50: 61.

14. Langford RW (2001) Navigating the maze of nursing research. St. louis: mosby pp: 1-152.

15. Holloway I, Wheeler S (2002) Qualitative research in nursing. Australia: Blackwell publishing p: 1-86.

16. Burns N, Grove S (2005) The practice of Nursing research, conduct, critique and utilization ( $5^{\text {th }}$ edn.), Philadelphia: WB Saunders pp:1-747.

17. Sooki Z, Sharifi KH (2007) Causes of Deportation of the Elderly to the kashan nursing home. p: 1-72.

18. Hogstel MO (2001) Gerontology: Nursing care of the older Adult. Albany, NY: Delmar Thomson Learning p: 1-75.

19. Seo H, Hollis V (2004) Remaining at home or moving to residential care: seniors' views. The Gerontologist 44(1): 636 .

20. Ghasemi H, Harirchi M, Masnavi A, Rahgozar M, Akbarian M (2011) Comparing the quality of life between elderly residents living in nursing homes and seniors living with their family members. Social Welfare Quarterly 10(39): 177-200. 
21. Fiveash B (1998) The experience of nursing home life. Int J Nurs pract 4(3): 166-174.

22. Wang JJ, Mitchell P, Smith W, Cumming RG, Leeder SR (2001) Incidence of nursing home placement in a defined community. Med J Aust 174(6): 271-275.
23. Abbasian M, Nakhodaeezah M, Namjoo S, Khalili Z, Jahangiry L, et al. (2019) Reasons for Nursing Home Placement of Older Women in Tabriz, Iran: A Content Analysis 13(4): 406-417. 